\title{
Particle Size Effects on Selectivity in Confined Bed Comminution
}

\author{
Holger Lieberwirth ${ }^{1, *(D)}$ and Lisa Kühnel ${ }^{2}$ \\ 1 Institute for Mineral Processing Machines and Recycling Systems Technology, TU Bergakademie Freiberg, \\ Lampadiusstr. 4, 09599 Freiberg, Germany \\ 2 Institute for Machine Elements, Engineering Design and Manufacturing, TU Bergakademie Freiberg, \\ Agricolastr. 1, 09599 Freiberg, Germany; Lisa.Kuehnel@imkf.tu-freiberg.de \\ * Correspondence: Holger.Lieberwirth@iam.tu-freiberg.de
}

Citation: Lieberwirth, H.; Kühnel, L. Particle Size Effects on Selectivity in Confined Bed Comminution. Minerals 2021, 11, 342. https://doi.org/ $10.3390 / \min 11040342$

Academic Editor: Luís Marcelo Tavares

Received: 31 December 2020

Accepted: 23 March 2021

Published: 26 March 2021

Publisher's Note: MDPI stays neutral with regard to jurisdictional claims in published maps and institutional affiliations.

Copyright: (c) 2021 by the authors. Licensee MDPI, Basel, Switzerland. This article is an open access article distributed under the terms and conditions of the Creative Commons Attribution (CC BY) license (https:/ / creativecommons.org/licenses/by/ $4.0 /)$.

\begin{abstract}
Confined bed comminution in high-pressure grinding rollers (HPGRs) and vertical roller mills (VRMs) was previously used preferably for grinding comparably homogeneous materials such as coal or clinker. Meanwhile, it started to complement or even replace tumbling mills in ore beneficiation with ore and gangue particles of rather different breakage behaviors. The selectivity in the comminution of a mixture of particles with different strengths but similar particle size distribution (PSD) of the constituents in a particle bed was investigated earlier. The strength of a material is, however, also a function of particle size. Finer particles tend to be more competent than coarser ones of the same material. In industrial ore processing using confined bed comminution, this effect cannot be neglected but even be exploited to increase efficiency. This paper presents research results on this topic based on experimental investigations with model materials and with natural particles, which were stressed in a piston-die press. It appeared that the comminution result substantially depends on the material characteristics, the composition of the mixture and the PSD of the constituents. Conclusions will be drawn for the future applications of selective comminution in mineral processing.
\end{abstract}

Keywords: confined bed comminution; HPGR; VRM; piston-die press; selective comminution

\section{Introduction}

\subsection{Confined Bed Comminution in Resource Industry}

The worldwide trend towards increased resource consumption, mainly driven by rising living standards of a growing world population, is unbroken [1,2]. On the other hand, newly discovered ore deposits exhibit a general trend toward lower grades [3,4]. As a result, increasing volumes of those lower-grade ores must be milled to liberate and recover the necessary quantities of valuable materials. Emissions from the production of materials as a share of global greenhouse gases increased from $15 \%$ in 1995 to $23 \%$ in 2015 [5]. The need for more efficient grinding methods is obvious [6,7].

Innovative grinding technologies such as high-pressure grinding rollers (HPGRs) or vertical roller mills (VRMs) have successfully demonstrated their efficiency, performance and durability in other industries, such as coal grinding or cement production for decades. In confined bed comminution, typical for both machine types, a bed of particles is exposed to a quasi-hydrostatic state of compression. Already Schönert and Fuerstenau found that this comminution principle is next to the single particle comminution, the most energy efficient way for particle size reduction [8,9].

Meanwhile, HPGR often complement or even replace more traditional mill types in ore beneficiation [10,11]. VRM only started to gain attention there [12]. It could be shown, however, that not only the energy efficiency of the grinding process is increased, but also the recovery in flotation was improved after dry grinding with a VRM [13].

The various phases in coal, limestone or clinker, exhibit a rather uniform fracturing behavior, at least compared with many ores. This means that the progenies of particles of the same-size report, with a certain scatter, to the same-size fraction, if the particles are 
stressed with the same load. Ores, ground in the confined bed of an HPGR or VRM, may respond differently to external loads.

Since HPGR were initially used mainly in the cement industry, selectivity in confined bed comminution was of limited interest and, respectively, only occasionally investigated. It came into the focus when the mining industry started to accept HPGRs for ore grinding and forms a core part of the Grade engineering idea promoted more recently by the CRC ore initiative [14,15]. The various minerals in an ore may exhibit different breakage behavior under the same load. As a result, the progenies of certain minerals may preferably report to finer fractions, while others remain in the coarser ones, thus causing grade differences among the fractions. This effect may negatively impact certain processing steps. When properly understood, however, it can even be used to efficiently produce a pre-concentrate just by screening.

\subsection{Selectivity in Comminution}

The effect that various constituents of a mixture, an ore or a composite material respond differently to an external load can be described by the term selective comminution. The technology has been applied in the industry for a long time already, preferably in connection with impact comminution [16,17]. More recently, Munro and Agbenuvor reported similar findings [18-20]. Hesse provided a comprehensive overview on observations of and investigations into selective comminution, citing more than 300 sources [21]. He concludes that the selective comminution is a system characteristic, depending on the material to be reduced in size and the comminution machine. The selectivity itself is a material property and arises from the differing breakage behavior of the various components of the feed material in a comminution machine.

Selective comminution, linked to impact loads, has been described in several papers. The effect occurs in confined bed comminution as well. The number of respective publications, however, is limited. Abouzeid and Fuerstenau reported the enhanced energy efficiency of grinding a mixture of quartzite and limestone in an HPGR [22]. The authors used a mixture with similar feed size distributions of both constituents. They reported that in the product, the weaker component, the limestone, reports preferably to finer fractions than the quartzite. The breakage behavior of the two components was different, obviously. Particles of the weaker component are subjected to breakage. With particles of the stronger component, the coarse fractions are merely broken as well, but the breakage of the finer particles or re-breakage of the progenies is a strong function of mixture composition and energy level.

Since the feed particle size distribution (PSD) of both components was nearly identical, the size effect on particle strength within both constituents was not investigated. The effect refers to the increasing strength of particles with decreasing size, already described by Schönert and Rumpf [23]. The number of defects in a particle is seen as the cause since cracks often start from defects. Defects are statistically distributed in the material and their number decreases with an decreasing volume of the particles [23-25]. The size-strength effect also explains the size dependency of the specific energy consumption described, among others in [26]. It may play an important role in the confined bed comminution of ores due to a different average grain size of the various minerals. It is overlaid, however, by the different inherent material strengths of those minerals, which would be reflected in the different uniaxial compressive strengths (UCSs) of the same-size particles of the various minerals. Due to the quasi-hydrostatic state of stresses in a confined particle bed, the particles of the weaker material should be subject to preferred comminution. This assumption was confirmed for a particle bed of same-size particles of different UCSs in [22]. An investigation of the overlaying influences of size effect and inherent material strength, typical for ore comminution with a respective variety of minerals and related grain sizes, is missing to date. This investigation is the subject of the research presented in this article. 


\subsection{Quantification of Selectivity and Selective Comminution}

Often, the change in the median particle size value $\varepsilon_{50}$, derived from the cumulative particle size distribution (PSD) curve, is used as a reference value for comminution considerations. If there are severe discontinuities in the PSD curve around that figure, as in the experiments described here, the $\varepsilon_{50}$ is not applicable. For the investigations described here, the selectivity $S$ is considered more suitable as a reference. The selectivity $S$ represents the normalized signed area of the region bounded by the cumulative PSD curves of two materials in the $Q_{3}(\mathrm{~d})$ diagram, cf. Figure 1.
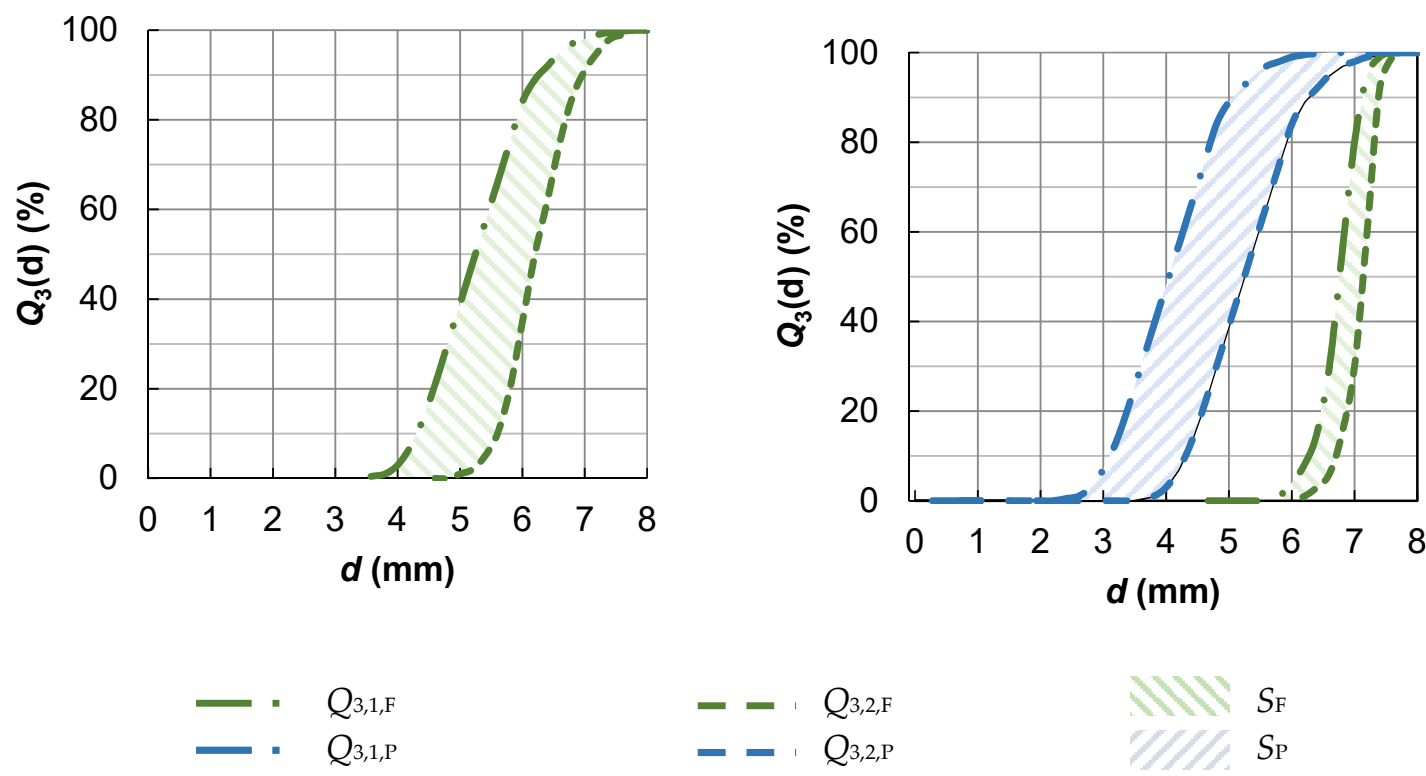

Figure 1. Example of the selectivity $S$ and selective comminution (SC) [27], left: selectivity in a feed material; right: shift in selectivity between the feed material (green) and product (blue) due to comminution.

The selectivity $S$ describes the differentiation of the components in a separation criterion [18]. Both a geometric and a material characteristic can be used as a separation criterion. In this article, the particle size $\mathrm{d}$ is used. For the calculation, the normalized difference between the integrals of the cumulative PSD curves $Q_{3}(\mathrm{~d})$ of two materials 1 and 2 is formed, Equation (1) with $\mathrm{d}_{u}$ and $\mathrm{d}_{o}$ as the lower and upper limit of the respective particle size range, respectively:

$$
S=\frac{\int_{d_{\mathrm{u}}}^{d_{\mathrm{o}}} Q_{3,1}(d) \mathrm{d} d-\int_{d_{\mathrm{u}}}^{d_{\mathrm{o}}} Q_{3,2}(\mathrm{~d}) \mathrm{d} d}{\mathrm{~d}_{o}-\mathrm{d}_{u}}
$$

The difference between the selectivity values of the feed $(\mathrm{F})$ and the product $(\mathrm{P})$ characterizes the actual result of the selective comminution. It is quantified by the value of the selective comminution SC, which is calculated according to Equations (2) and (3):

$$
\begin{gathered}
S C=S_{\mathrm{P}}-S_{\mathrm{F}} \\
S C=\frac{\int_{d_{\mathrm{u}}}^{d_{\mathrm{o}}} Q_{3,1, \mathrm{P}}(d) \mathrm{d} d-\int_{d_{\mathrm{u}}}^{d_{\mathrm{o}}} Q_{3,2, \mathrm{P}}(d) \mathrm{d} d}{\mathrm{~d}_{o}-\mathrm{d}_{u}}-\frac{\int_{d_{\mathrm{u}}}^{d_{\mathrm{o}}} Q_{3,1, \mathrm{~F}}(d) \mathrm{d} d-\int_{d_{\mathrm{u}}}^{d_{\mathrm{o}}} Q_{3,2, \mathrm{~F}}(d) \mathrm{d} d}{\mathrm{~d}_{o}-\mathrm{d}_{u}}
\end{gathered}
$$

When using the formulas, it is important to recognize that both the values for $S_{\mathrm{F}}$ and $S_{P}$ are signed depending on the size distribution. Thus, $S C$ may assume positive and negative values, depending on the direction of selectivity changes in comminution. In addition, no change in the $S C$ value can be determined if there is only a shift of two associated PSD curves (either the feed and/or the product). 


\section{Experimental}

\subsection{Experimental Material}

The selection of the experimental materials is based on the objectives of the work. Both basic investigations with ideal spherical particles and the selective comminution with real rocks are examined. Based on extensive material research and the subsequent determination of important material parameters, glass and aluminum oxide (corundum) balls were selected as the ideally round particles ("Diamond Pearls", made by Mühlmeier $\mathrm{GmbH} \&$ Co. KG, Bärnau, Germany), cf. Figure 2. The circularity of the balls was at least $98 \%$, and the remaining parameters of the materials are indicated in Table 1.

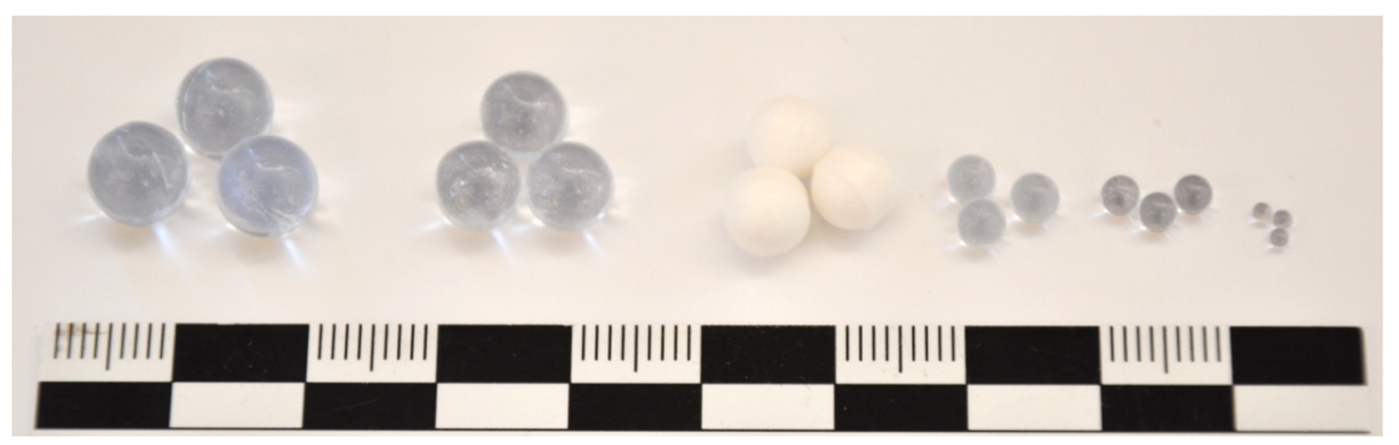

Figure 2. Glass balls $(\mathrm{G})$ and corundum balls $(\mathrm{C})$ sorted from left to right according to their diameter in mm (G8/G7/C7/G4/G3/G1.5) [27].

Table 1. Glass balls (G) and corundum balls (C), technical data.

\begin{tabular}{ccccc}
\hline Material & $\begin{array}{c}\text { Nominal } \\
\text { Diameter }(\mathbf{m m})\end{array}$ & $\begin{array}{c}\text { Mean Diameter/ } \\
\text { Scatter }(\mathbf{m m})\end{array}$ & $\begin{array}{c}\text { Breakage } \\
\text { Strength }\left(\mathbf{N} / \mathbf{m m}^{2}\right)\end{array}$ & $\begin{array}{c}\text { Relative Breakage } \\
\text { Strength (\%) })^{*}\end{array}$ \\
\hline Glass & 1.5 & $1.60 \pm 0.03$ & $420 \pm 40$ & 132.5 \\
$($ Density: & 3.0 & $3.10 \pm 0.03$ & $235 \pm 20$ & 74.1 \\
$\left.2.52-2.56 \mathrm{~g} / \mathrm{cm}^{3}\right)$ & 7.0 & $7.00 \pm 0.09$ & $143 \pm 12$ & 45.1 \\
\hline $\begin{array}{c}\text { Corundum } \\
\left(3.72 \pm 0.02 \mathrm{~g} / \mathrm{cm}^{3}\right)\end{array}$ & 7.0 & $6.67 \pm 0.07$ & $317 \pm 40$ & 100.0 \\
\hline
\end{tabular}

*) mean values, relative to $d=7 \mathrm{~mm}$ corundum balls.

The diameters and sphericity were measured using photo-optical analysis methods (CPA, Haver and Boecker and CAMSIZER ${ }^{\circledR}$ P4, Retsch Technology, Haan, Germany). In the following, the term fraction is used for balls of the same nominal diameter. The breakage strength of 30 balls per fraction was determined using the materials testing device UNIMAT $^{\circledR}$ (ERICHSEN, Hemer, Germany). While for the same-size fraction $d=7 \mathrm{~mm}$, the breakage strength of glass is only $45.1 \%$ of the corundum one, and the strength for the $d=1.5 \mathrm{~mm}$ glass balls is $132.5 \%$.

Figure 3 shows selected fractions of the rocks used for the investigations. The quartzite is from an alluvial deposit near Ottendorf-Okrilla, Germany. The limestone was supplied by a quarry near Brilon, Germany. Before classifying, it was initially crushed by jaw crusher, in the second step by hammer crusher with $10 \mathrm{~mm}$ grate to produce particles of predominantly cubicle shape. The quartzite was only classified. It consisted of $100.0 \%$ quartz, while the limestone contained $95.2 \%$ calcite, $4.0 \%$ dolomite and less than $1.0 \%$ quartz. The standardized point load strength $\mathrm{I}_{\mathrm{s}(50)}$ of the two materials was determined (30 test samples each) to be $\mathrm{I}_{\mathrm{S}(50)}=4.70 \pm 0.36 \mathrm{~N} / \mathrm{mm}^{2}$ for the limestone and $\mathrm{I}_{\mathrm{s}(50)}=6.86 \pm 2.59 \mathrm{~N} / \mathrm{mm}^{2}$ for the quartzite. Testing the strength of various particle sizes for both materials, a size dependence was confirmed. It was established that particles of the limestone fraction of $0.9-1.1 \mathrm{~mm}$ have the same strength as quartz particles of the $7.1-8 \mathrm{~mm}$ fraction. For the same strength experiments, a limestone particle fraction of 1-1.4 mm was used, acknowledging that the strength of the particles of this fraction is slightly lower than that of the $7.1-8 \mathrm{~mm}$ quartz fraction. 


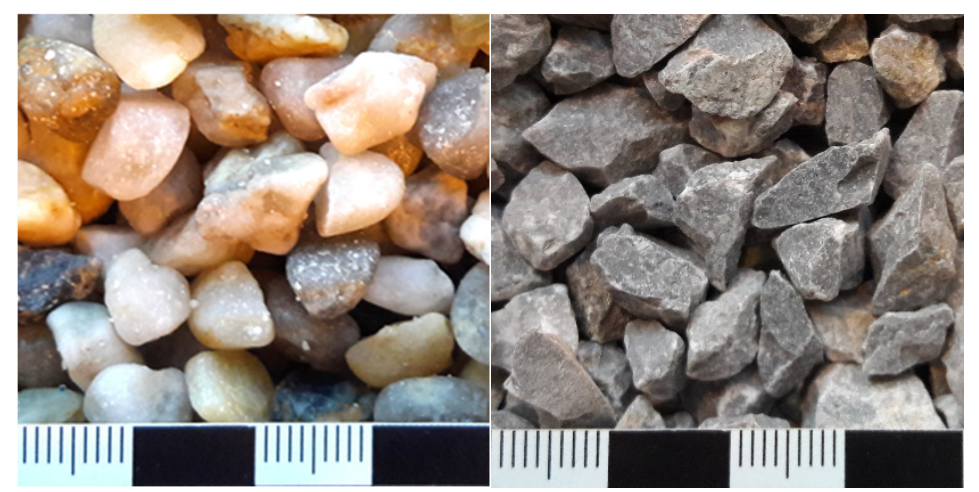

Figure 3. Quartzite (left, 7.1/8 mm) and limestone (right, 5.6/8 mm).

After the tests, the different material constituents of the comminution products were separated by manual picking for the coarser particles and using the density difference between glass and corundum as well as the different solubility in hydrochloric acid to separate the quartzite from the limestone for the finer particles.

\subsection{Piston-Die Test Rig}

A common way to investigate confined bed comminution problems is to use a pistondie test rig. Piston-die tests have been widely used to investigate aspects of confined bed comminution, for instance by [28-30]. Compared to tests on VRM or HPGR, the amount of test material for each experiment was much smaller. If the conditions of an ideal confined bed are respected, the results of a piston-die test can also be considered as representative of other confined bed applications with similar conditions. The parameters of the experimental tests met the requirements to ideal confined beds according to [24]. The principal configuration of the test rig is shown in Figure 4.

The piston-die tests were conducted on a 4-column hydraulic press, type KV 135.02 (Rucks Maschinenbau GmbH, Glauchau, Germany). The main experimental parameters were:

- Die diameter and height: $160 \mathrm{~mm} \times 135 \mathrm{~mm}$;

- Compression velocity: $10 \mathrm{~mm} / \mathrm{s}$;

- $\quad$ Resulting average pressure: $62.5 \mathrm{MPa}$;

- Initial confined bed height: $50 \mathrm{~mm}$.

Calibrated load cells underneath the die measured the forces acting on the particle bed, while a laser device measured the piston path. Forces relative to displacement were recorded together with the piston displacement. The area below the curve in the resulting force-displacement diagram plot is a good measure of the energy spent in the test.

\subsection{Experimental Program}

Table 2 shows the experimental program this paper is based on. Experiments were conducted for artificial particles (balls from glass and corundum) and natural materials (limestone and quartzite). In both cases, various mixtures of the material of higher compressive strength, subsequently called stronger material, ("Fraction 1", always the same-size fraction) and a size fraction of the material with the lower UCS, subsequently called the weaker material, ("Fraction 2") were stressed. For each combination, all indicated mixtures were investigated. 


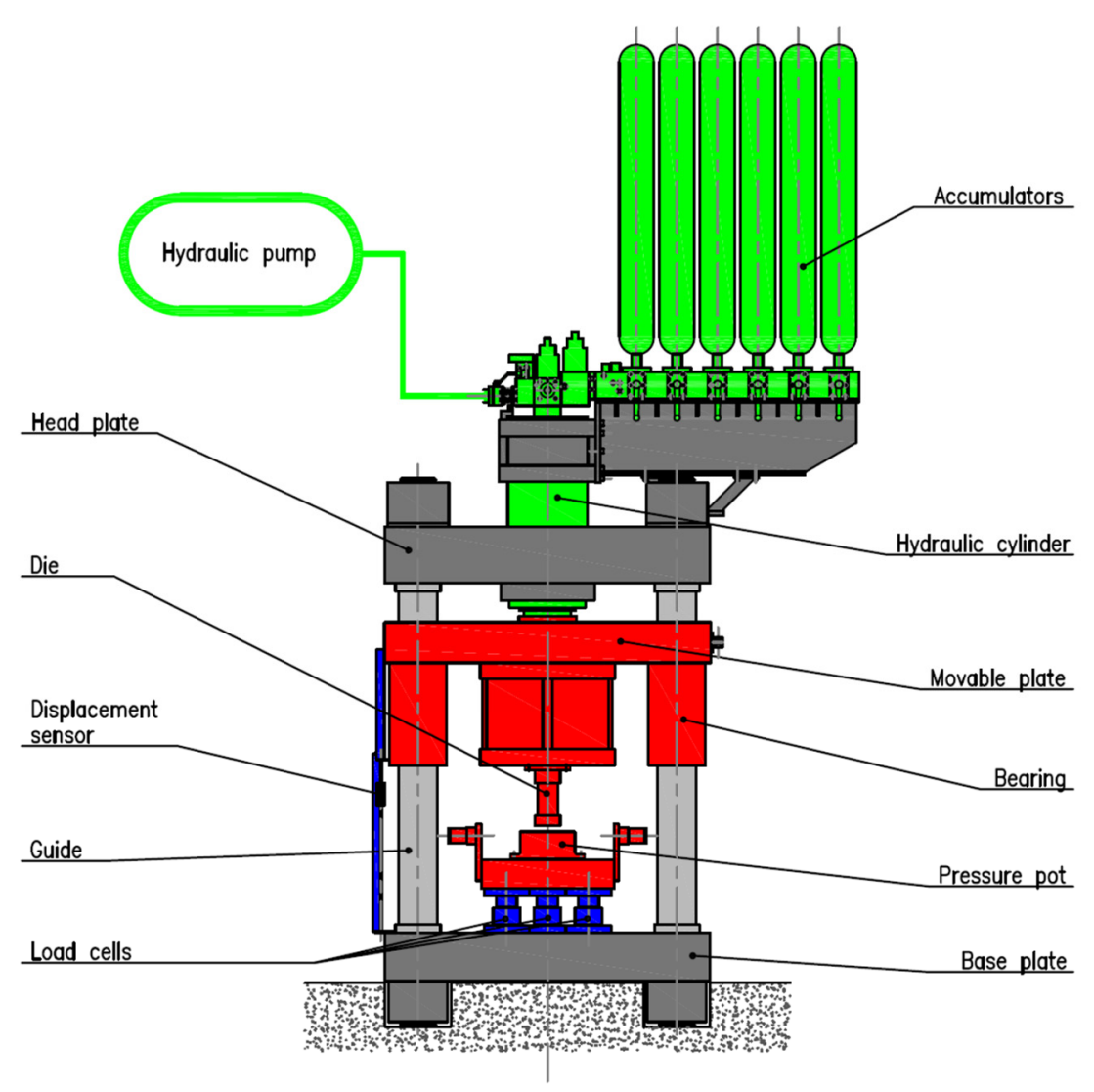

Figure 4. Piston-die test rig (schematic) [27].

Table 2. Experimental program.

\begin{tabular}{cccc}
\hline \multirow{2}{*}{ Material } & \multicolumn{2}{c}{ Mean Particle Diameter $(\mathbf{m m})$} & Mixture (Vol \%) \\
\cline { 2 - 3 } & Fraction 1 & Fraction 2 & \\
\hline \multirow{2}{*}{ Corundum/glass } & & & $100 / 0$ \\
& 7.0 & 1.5 & $90 / 10$ \\
& & 7.0 & $\left.75 / 25^{*}\right)$ \\
& & & $\left.66 / 34^{* *}\right)$ \\
Quartzite/limestone & \multirow{2}{*}{$7.1 / 8.0$} & $1.0 / 1.4$ & $50 / 50$ \\
& & $7.1 / 8.0$ & $25 / 75$ \\
& & & $10 / 90$ \\
\hline
\end{tabular}

*) Quartzite/limestone only, ${ }^{* *}$ ) Corundum/glass only.

\section{Results and Discussion}

This section presents and discusses the results for the confined bed comminution of various mixtures of corundum and glass as well as of quartzite and limestone in pistondie tests. Results are discussed in terms of the selective comminution of the various constituents. Figure 5 shows the relationship between the $S C$ value and the composition of mixtures of quartzite and limestone. The $x$ axis indicates the proportion of the quartzite in the mixture. The proportion of limestone makes up the balance of $100 \%$. Positive SC values indicate a preferred breakage of the limestone, while negative $S C$ values indicated a preferred breakage of the quartz. The three red triangular shapes shown for the $50 \%$ quartz content represent three repeated tests with the same parameters, proving the good repeatability of the tests conducted. 


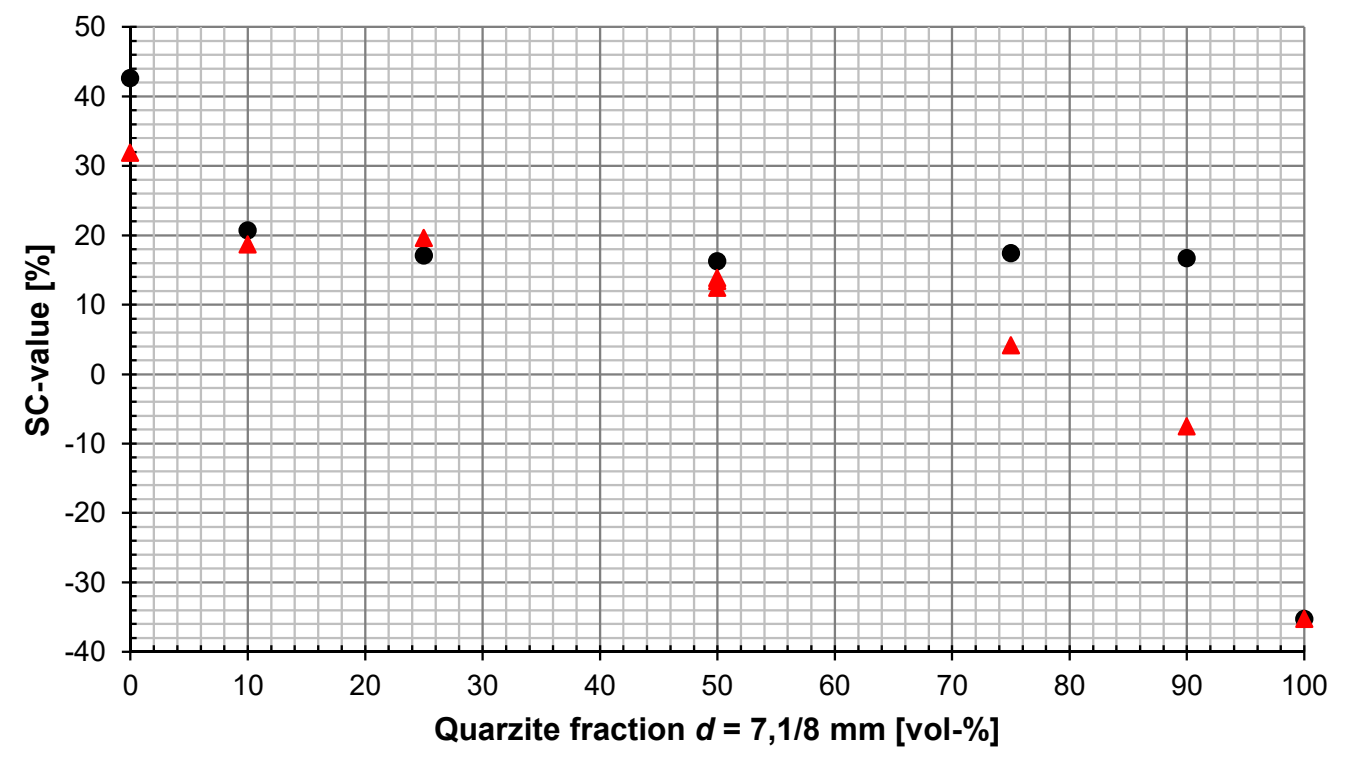

- limestone $\mathrm{d}=7.1-8 \mathrm{~mm} \quad \Delta$ limestone $\mathrm{d}=1-1.4 \mathrm{~mm}$

Figure 5. Selective comminution for mixtures of narrow fractions of quartzite and limestone.

The results of the test for the same-size particle fractions of quartz and limestone $\left(d_{F}=7.1-8.0 \mathrm{~mm}\right.$, filled black circles) indicate for all bi-dispersed mixtures a preferred comminution of the limestone particles with $S C$ values being all in a narrow band $(S C=16-20 \%)$. Only the figures for the pure fractions (100\% limestone, $100 \%$ quartzite) exhibit strongly deviating numbers to the respective directions. These results correspond to the results of tests of similar mixtures in an HPGR by [22]. It is confirmed that in case of the same-size fractions of materials with different breakage strengths, the weaker material is preferably broken. The composition of the mixture only has a significant effect if one constituent represents more than $90 \%$ of the mixture. Due to the sheer number of contacts, this constituent is preferably broken, irrespective of whether it is the stronger or weaker material. This results in an S-shaped graph for the $S C$ values, if all mono- and bi-dispersed fractions are included (0 to $100 \%$ quartzite).

Such an S-shaped graph can also be found for the tests, if a mixture of narrow fractions of coarser quartzite $\left(d_{\mathrm{f}, \mathrm{q}}=7.1-8.0 \mathrm{~mm}\right)$ and substantially finer limestone particles $\left(d_{\mathrm{f}, \mathrm{l}}=1.0-1.4 \mathrm{~mm}\right)$ is stressed. Here, due to the size-strength effect, the finer limestone particles exhibit similar breakage strength as coarser quartz particles (red triangles). Beyond $25 \%$ quartzite content, the $S C$ values strongly decrease with increasing quartzite content. Beyond around $75 \%$ quartzite content in the mixture, the $S C$ values change to negative, indicating a preferential comminution of the quartzite particles. The $75 \%$ range coincides with the zone of the densest possible packing of the finer limestone particles between the coarser quartz particles.

Since for the mixture of quartzite and limestone particles, other influences such as particle shape and fraction width, may play a role, in a further experiment, mixtures of single size corundum with glass balls are used to investigate the influence of the sizestrength effect on selective comminution. Figure 6 shows that for particle beds consisting of mixtures of the same-size glass and corundum balls (filled black circles), the glass balls are preferably broken. Only the particle bed consisting of $100 \%$ corundum balls shows, not surprisingly, a higher amount of broken corundum balls than glass balls. Another obvious result of this experiment is that in the range of $50-66 \%$ corundum ball content, the highest selectivity values were measured. It can be concluded that the presence of a substantial fraction of stronger material particles supports the preferential breakage of the same-size particles of the weaker material. 


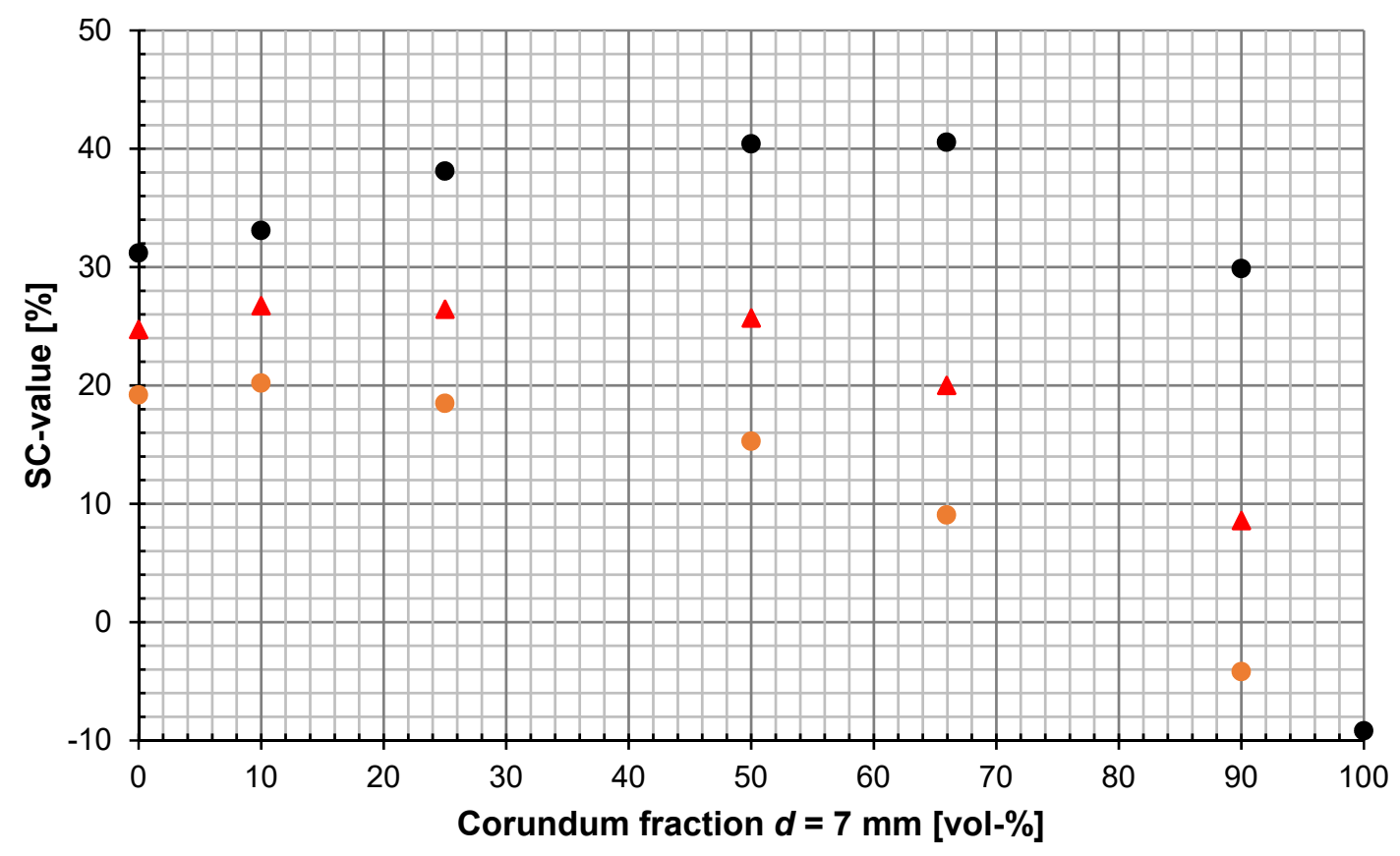

- glass $\mathrm{d}=7 \mathrm{~mm} \quad \Delta$ glass $\mathrm{d}=3 \mathrm{~mm} \quad$ glass $\mathrm{d}=1.5 \mathrm{~mm}$

Figure 6. Selective comminution of mixtures of a corundum fraction with various glass fractions.

This effect is superimposed, however, by the size-strength effect, if particles of different size fractions are mixed. The finer the glass balls are, the earlier the equilibrium point is reached, beyond which the corundum particles are preferentially comminuted. For glass balls of $3 \mathrm{~mm}$ diameter, this point is still beyond $90 \%$ corundum ball content in the mixture, and for $1.5 \mathrm{~mm}$ glass balls this point is between $66 \%$ and $90 \%$ corundum ball content.

\section{Conclusions}

This study investigated the selectivity in the confined bed comminution of mixtures of narrow fractioned glass and corundum balls as well as of mixtures of quartzite and limestone particles. For those artificial and natural materials, it was shown that the sizestrength effect plays an important role in selectivity in confined bed comminution. With the same-size particle fractions, the fraction of the weaker material is preferentially broken. In the case of a mixture of around $50 \%$ each of particles of stronger and weaker material, a maximum in selective comminution of the weaker material fraction was shown. In the case of the different particle sizes of the stronger and weaker material that picture changes, however. Due to the size-strength effect, the finer particles are relatively stronger and the coarser particles of the stronger material may be subjected to preferential breakage. That effect should be of particular interest for the confined bed comminution of ores, where the different mineral constituents not only exhibit different breakage strength but also different particle size distributions.

A typical example of such an effect might be the confined bed comminution of a gold ore, consisting of finely disseminated gold grains in a quartzite gangue material. In traditional ball milling/hydro-cyclon-circuits, a portion of the soft gold grains may be lost due to overgrinding and a platy grain shape caused by grain forging in the milling process. The size-strength effect in a confined bed comminution should reduce the overgrinding and eliminate the platy deformation of gold grains and thus increase gold recovery. This assumption will be investigated with real ores in future tests with HPGR and VRM. These tests shall also be used to validate the $S C$ value approach as a potential future standard tool for quantifying selectivity after breakage tests. The $S C$-value index presented in this paper has the potential to be used as a standard tool for qualifying selectivity after breakage 
tests. Its potential for producing grade recovery curves used by industry for characterizing different ore types will need to be further investigated.

Author Contributions: Conceptualization, L.K. and H.L.; methodology, L.K.; validation, H.L. and L.K.; formal analysis, L.K.; investigation, L.K.; resources, H.L.; data curation, L.K.; writing-original draft preparation, H.L.; writing-review and editing, L.K.; visualization, L.K.; supervision, H.L.; project administration, H.L.; funding acquisition, H.L. All authors have read and agreed to the published version of the manuscript.

Funding: The authors would like to thank the SAXON DEVELOPMENT BANK for supporting this research project.

Data Availability Statement: Data available on request.

Conflicts of Interest: The authors declare no conflict of interest.

\section{References}

1. Krausmann, F.; Gingrich, S.; Eisenmenger, N.; Erb, K.-H.; Haberl, H.; Fischer-Kowalski, M. Growth in global materials use, GDP and population during the 20th century. Ecol. Econ. 2009, 68, 2696-2705. [CrossRef]

2. European Commission. Raw Materials Scoreboard: European Partnership on Raw Materials. 2016. Available online: https: / / op.europa.eu/en/publication-detail/-/publication/1ee65e21-9ac4-11e6-868c-01aa75ed71a1 (accessed on 25 March 2021).

3. Schodde, R. The key drivers behind resource growth: An analysis of the copper industry over the last 100 years. In Proceedings of the SME (ed) 2010 MEMS Conference Mineral and Metal Markets over the Long Term, Joint Program with the SME Annual Meeting, Phoenix, AZ, USA, 3 March 2010.

4. Talovina, I.V.; Lieberwirth, H.; Alexandrova, T.N.; Heide, G.G. Supergene oxide-silicate nickel deposits: Mineral-geochemical composition and peculiarities of processing. Eurasian Min. 2017, 2017, 21-24. [CrossRef]

5. Hertwich, E.; Lifset, R.; Pauliuk, S.; Heeren, N.; Ali, S.; Tu, Q.; Ardente, F.; Berrill, P.; Fishman, T.; Kanaoka, K. Resource efficiency and climate change: Material efficiency strategies for a low-carbon future. In A Report of the International Resource Panel; United Nations Environment Programme: Nairobi, Kenia, 2020.

6. Schodde, R. Role of Technology and Innovation for Identifying and Growing Economic Resources. Available online: http: //minexconsulting.com/role-of-technology-and-innovation-for-identifying-and-growing-economic-resources/ (accessed on 25 March 2021).

7. Ballantyne, G.R.; Powell, M.S. Benchmarking comminution energy consumption for the processing of copper and gold ores. Miner. Eng. 2014, 65, 109-114. [CrossRef]

8. Fuerstenau, D.W.; Shukla, A.; Kapur, P.C. Energy consumption and product size distributions in choke-fed, high-compression roll mills. Int. J. Miner. Process. 1991, 32, 59-79. [CrossRef]

9. Fuerstenau, D.W.; Kapur, P.C.; Schoenert, K.; Marktscheffel, M. Comparison of Energy Consumption in the Breakage of Single Particles in a Rigidly Mounted Roll Mill with Ball Mill Grinding. Int. J. Miner. Process. 1990, 28, 109-125. [CrossRef]

10. Villanueva, A.; Banini, G.; Butar-Butar, R. (Eds.) Effects of HPGR Introduction on Grinding Performance at PT Freeport Indonesia's Concentrator; Canadian Institute of Mining, Metallurgy and Petroleum: Vancouver, BC, Canada, 2011.

11. Chanturiya, V.A. Innovation Based Process of Integrated and High-Level Processing of Natural an Technogenic Minerals in Russia. In Proceedings of the IMPC 2018-29th International Mineral Processing Congress, Moscow, Russia, 17-21 September 2018.

12. Altun, D.; Benzer, H.; Aydogan, N.; Gerold, C. Operational parameters affecting the vertical roller mill performance. Miner. Eng. 2017, 103, 67-71. [CrossRef]

13. Reichert, M.; Gerold, C.; Fredriksson, A.; Adolfsson, G.; Lieberwirth, H. Research of iron ore grinding in a vertical-roller-mill. Miner. Eng. 2015, 73, 109-115. [CrossRef]

14. CRC Ore Introducing CRC for Optimization of Extraction. Available online: https://crca.asn.au/wp-content/uploads/2014/06/ 03-CRCORE-Overview-for-CRCA-Conference-May-2014.pdf (accessed on 25 March 2021).

15. Walters, S.G. Driving Productivity by Increasing Feed Quality Through Application of Innovative Grade Engineering ${ }^{\circledR}$ Technologies. 2016. Available online: https://crcore.org.au/images/CRC-ORE/papers/Walters-S-2016-Grade-Engineering-Whitepaper. pdf (accessed on 12 March 2021).

16. Puffe, E. Betriebskostenersparnis durch Vorkonzentration erläutert am Beispiel Mechernich. Erzmetall 1955, 8, B29-B38.

17. Puffe, E. Selektive Prallzerkleinerung als Mittel zur Senkung der Betriebskosten und zur Erhöhung des Ausbringens in Aufbereitungsanlagen. Glückauf Berg und Hüttenmännische Z. 1960, 96, 20-30.

18. Agbenuvor, B.S. Investigation into Multi-Stage Impact Breakage. Master's Thesis, University of Queensland, Brisbane, Austrilia, 2020.

19. Agbenuvor, B.S.; Antonio, C.; Jokovic, V.; Morrison, R. Enhancing Coarse Gangue Rejection through Controlled and Precise Multistage Impact Breakage. In Proceedings of the Physical Separation Conference 2019, Falmouth, UK, 13-14 June 2019.

20. Munro, P.; Schache, I.; Park, W.G.; Watsford, R.M.S. The design, construction and commissioning of a heavy medium plant for silver-lead-zinc ore treatment Mount Isa Mines Limited. In Proceedings of the 14th International Processing Conference (IMPC), Toronto, ON, Canada, 17-23 October 1982. 
21. Hesse, M. Selektive Zerkleinerung von Erzen und Industriemineralen bei Prallbeanspruchung. Ph.D. Thesis, TU Bergakademie Freiberg, Freiberg, Germany, 2017.

22. Abouzeid, A.-Z.M.; Fuerstenau, D.W. Grinding of mineral mixtures in high-pressure grinding rolls. Int. J. Miner. Process. 2009, 93, 59-65. [CrossRef]

23. Schönert, K.; Rumpf, H. Versuche zur Zerkleinerung von Einzelteilchen zwischen zwei Flächen. Symp. Zerkleinern 1962, 3 , 108-127.

24. Schönert, K. The influence of particle bed configurations and confinements on particle breakage. Int. J. Miner. Process. 1996, 44, 1-16. [CrossRef]

25. Weichert, R. Anwendung von Fehlstellenstatistik und Bruchmechanik zur Beschreibung von Zerkleinerungsvorgängen. Zem. Kalk Gips 1992, 45, 1-8.

26. Abouzeid, A.; Seifelnassr, A.; Zain, G.; Mustafa, Y.S. Breakage Behavior of Quartz Under Compression in a Piston Die. Min. Metall. Explor. 2019, 36, 173-180. [CrossRef]

27. Kühnel, L. Untersuchungen Zur Gutbettzerkleinerung in Einer Hydraulischen Stempelpresse. Ph.D. Thesis, TU Bergakademie Freiberg, Freiberg, Germany, 2019.

28. Mütze, T. Modellhafte Beschreibung des Beanspruchungsverhaltens geschlossener Gutbetten. Chem. Ing. Tech. 2014, 86, 814-820. [CrossRef]

29. Schnatz, R. Verarbeitungseigenschaften von Zement bei der Fertigmahlung in Mahlanlagen mit Gutbett-Walzenmühle. Ph.D. Thesis, Technische Universität Clausthal, Clausthal-Zellerfeld, Germany, 1998.

30. Heinicke, F. Beitrag zur Modellierung der Zerkleinerung in Gutbettwalzenmühlen. Ph.D. Thesis, RWTH Aachen, Aachen, Germany, 2012. 